\title{
POLARIZATION-ANGULAR DEPENDENCES OF THE REFLECTION AND TRANSMISSION COEFFICIENTS OF FREE PLATES OF QUASI-ANISOTROPIC ICE IN THE L-RANGE
}

\author{
Mikhail G. Evtikhov, Galina V. Arzamastseva \\ Kotelnikov Institute of Radioengineering and Electronics of RAS, Fryazino Branch, http://fire.relarn.ru \\ Fryazino 141190, Moscow Region, Russian Federation \\ emg20022002@mail.ru, arzamastseva@mail.ru
}

Abstract. The polarization-angular dependences of the reflection and transmission coefficients of free plane-parallel ice plates in the region of $0^{\circ} \mathrm{C}$, when flat electromagnetic waves of s- and p-polarization fall on them and are recorded by an L-band radiometer $1.41 \mathrm{GHz}$ are studied theoretically. It is shown that the observation of interference effects in ice plates in the L-range is limited to a plate thickness of 4.3 meters. This limitation is due to a radiometer bandwidth of $20 \mathrm{MHz}$. Ice is considered an isotropic or uniaxial crystal with an anisotropy coefficient of $15 \%$. Three types of directions of the anisotropy axis are considered in the assumptions of the quasianisotropic medium model. The value of the Brewster angle is obtained, and it is shown that it does not depend on anisotropy. Reflective and anti-reflective effects are associated with a change in wavelength in the direction perpendicular to the surface of the plate. In turn, this length depends on the angle of incidence, polarization, and direction of the anisotropy axis. The possibility of forming interference regions of transparency for certain thicknesses is shown, the reflection coefficients for both polarizations are significantly reduced, and the transmittances increase. Interference areas of transparency can be formed both at the Brewster angle and at other angles. These effects are associated with interference phenomena and their enhanced effect of anisotropy.

Keywords: reflection, refraction, Fresnel equations, permittivity, millimeter waves, ice, resonance, multilayer plates.

UDC 0535.391.4, 53.082.53, 53.083.2

Bibliography - 30 references

Received 18.03.2019, accepted 05.04.2019

RENSIT, 2019, 11(1):73-84

DOI: $10.17725 /$ rensit.2019.11.073

\section{Contents}

1. INTRODUCTION (73)

2. Selection of coordinate AXes AND ASSUMPTIONS OF THE MATHEMATICAL MODEL (74)

3. CONDITIONS OF INTERFERENCE EFFECTS FOR FREE PLATES OF ICE AT VARIOUS ANGLES OF INCIDENCE (75)

4. The EFFect of ANisotropy ON THE WAVELENGTH (75)

5. EnhanCing the INFLUENCE OF X-ANisotropy BY INTERFERENCE EFFECTS (76)

6. Examples OF AREAS OF TRANSPARENCY IN SINGLE-LAYER AND THREE-LAYER PLATES (76)

7. Maximum thickNess of ice plates of OBSERVATION OF INTERFERENCE STRUCTURES IN THE L-BAND (76)

8. Conclusion (77)

Appendix (78)

REFERENCES (78)

\section{INTRODUCTION}

Applications of the general theory of linear electromagnetic waves of anisotropic media [1, $2,3]$ require the agreement of general methods based on linear algebra and more traditional approaches to solving diffraction problems. Solutions of many problems of optics $[1,4,5]$, acoustics [6], ellipsometry [7], X-ray optics [8, 9] and remote sensing of the environment [10] are based on the use of Fresnel and Fresnel-Airy coefficients. However, in the Fresnel formulas, radiation is assumed to be monochromatic, and the media should be isotropic. The observed interference structures of microwave radiation depend on the bandwidth of the radiometer. Structures are considered theoretically in the case of normal incidence of radiation in 
[11]. The class of quasi-anisotropic multilayer plates is considered in [12-14]. This class includes anisotropic media, where $s$ - and p-polarized waves propagate independently. A generalization of Fresnel-Airy formulas to quasi-anisotropic media is considered in [14]. The combination of the methods from [11] and [14] makes it possible to theoretically investigate the effect of anisotropy on the reflection and transmission coefficients of electromagnetic radiation. This paper discusses free ice plates in the L-range.

The Fresnel-Airy coefficients, reflection and transmission coefficients are used in radiometric methods for calculating the brightness temperature of the controlled surface [10]. At frequencies of $1 \mathrm{GHz}-$ $100 \mathrm{GHz}$, ice, snow, and other types of the earth's surface are studied for a long time $[10,15-22]$. In the range above $2 \mathrm{GHz}$, the behavior of the Fresnel-Airy coefficients of ice plates is complicated by the nonmonotonic dependence of the dielectric constant on frequency, as well as by the presence of microcracks [20]. It was reported about the observation of Ginzburg-Pekar waves in this range, near $0^{\circ} \mathrm{C}$ [24-25]. The complexity of physical phenomena in ice at high frequencies makes the L-band (1-2 $\mathrm{GHz}$ ) promising for theoretical study. The wavelengths of the L-range are about 20 $\mathrm{cm}$ in vacuum and about $10 \mathrm{~cm}$ for ice; the Debye formula for the dielectric constant of ice remains valid in it, which simplifies adequate mathematical models. The results of this paper for the L-range should allow to separate the influence of anisotropy from more complex phenomena in other ranges. The presence of mass-produced domestic and foreign $L$-band radiometers [17, 22, 23] creates the prospect of practical applications of theoretical results.

The practical significance of studying the electric and acoustic anisotropy of ice is substantiated by the significant effect of anisotropy on the wave processes in sea ice [26]. It is noted that the dielectric anisotropy and anisotropy of the elastic properties of ice may not coincide. In [27], [28], ice is considered as a uniaxial crystal and is characterized by the anisotropy coefficient. For ice-1, the anisotropy of the dielectric constant in the microwave range is approximately 15\% [27]. Laboratory experiments to measure the anisotropy of the dielectric constant and specific absorption of arctic drift ice in the microwave range are described in [28], values from $2 \%$ to $15 \%$ for old ice were obtained, it was noted that the new ice layers are isotropic. Various variants of the direction of the anisotropy axis with respect to the direction of propagation of microwave radiation were considered.

Free plates are of interest for laboratory research, their consideration is a necessary stage in the development of new algorithms. Interference effects in free plates appear more clearly, and the calculation of transmittance is simpler.

In this paper, we restrict ourselves to the consideration of free plates.

The aim of the article is to theoretically consider the influence of ice anisotropy and non-monochromatic radiation on polarizationangle diagrams of reflection and transmission coefficients of L-band electromagnetic waves for free plane-parallel ice plates assuming that the medium is quasi-anisotropic.

\section{SELECTION OF COORDINATE AXES AND ASSUMPTIONS OF THE MATHEMATICAL MODEL}

In Fig. 1, we denote the wave number in parentheses, and the medium number in square brackets. The $x$-axis is orthogonal to the ice surface. The medium [1] and the medium [3] are air (vacuum). The medium [2] is isotropic or anisotropic ice. The axis of coordinates $y$ is parallel to the projection of the wave vector of the wave in vacuum onto the interface 
between the media. The axis of coordinates $z$ is orthogonal to the plane of the figure and is directed to the reader, it lies in the plane of the surface of the plate. The incident wave is indicated by a number 0 . The reflected wave has the number 1 . The refracted wave in the medium 1 has the number 2 , the reflected wave in the medium 2 has the number 3 . The wave coming out of the plate has the number 4. When calculating the amplitudes of waves 3 and 4 , their multiple reflections are taken into account according to the algorithms [15]. We consider the wave with elliptical polarization as two independently propagating linearly polarized waves with $s$ - and $p$-polarizations. The electric field of a wave with $s$-polarization is directed along the $z$ axis. It is convenient to define a wave with $p$-polarization (like $s$-polarization), as a wave whose magnetic field is directed along the axis [1]. As the magnitude of the amplitude of a wave with $p$-polarization, is used. This Such a definition is adequate in media with absorption. In the algorithms used in this work from [15], the angle of refraction is not fundamentally applicable. Instead of them, in accordance with the approach [1], complex wave vectors are considered. Therefore, it is possible to speak of the angle of refraction only formally, as of the real part of the corresponding complex value.

In quasi-anisotropic media, wave vectors (angles of refraction) and wave propagation speeds for $s$ - and $p$-polarizations should

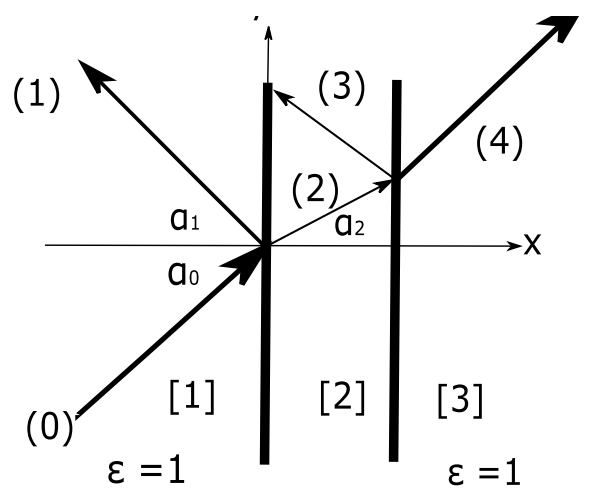

Fig.1. Wave vectors in the free plate. differ. Further, speaking of $x$-anisotropy, we will consider a uniaxial crystal, in which the anisotropy axis is directed along the $x$-axis, orthogonal to the surface of the ice plate. Similarly, we will speak of $y$ - and z-anisotropy as cases when the anisotropy axis is parallel to the ice surface. We assume that there is no spatial dispersion and dispersion of the axes. Then waves with $s$ - and $p$-polarizations can be identified with the concepts of "ordinary" and "extraordinary" waves adopted in the optics of anisotropic media (see Appendix).

Angles of wave propagation are measured relative to the normal to the plate surface. The article deals only with free plates in a vacuum. Further, the terms "angle of incidence", "angle of observation" are used as equivalent. For a free plate, the angle of incidence is equal to the angle of reflection and equal to the angle of the direction of propagation of the wave leaving the plates, all angles being equal and real. The transmittance and reflection coefficients of the free plates are equal to the square of the modules of the Fresnel-Airy coefficients. $\left|R_{s}\right|^{2}$ ,$\left|T_{s}\right|^{2}$ - reflection and transmission coefficients for waves with $s$-polarization. $\left|R_{p}\right|^{2}$ и $\left|T_{p}\right|^{2}-$ for waves with $p$-polarization.

In the calculations, the value of the relative complex dielectric constant of ice near $0^{\circ} \mathrm{C}$ is equal to $\varepsilon=3.18+0.0007 i[16,29,30]$. The value of the imaginary part varied within $15 \%$, real $-2 \%$, the changes did not significantly affect the results.

\section{CONDITIONS OF INTERFERENCE EFFECTS FOR FREE PLATES OF ICE AT VARIOUS ANGLES OF INCIDENCE}

The wave vector can be decomposed into the ortes of the coordinate axes $\left(\mathbf{e}_{\mathrm{x}}, \mathbf{e}_{\mathrm{y}}, \mathbf{e}_{z}\right)$ and can be represented through the wavelengths in the corresponding directions, noting some conventionality of such a term:

$$
\mathbf{k}=\mathbf{k}_{x}+\mathbf{k}_{y}+\mathbf{k}_{z}=\frac{2 \pi}{L_{x}} \mathbf{e}_{x}+\frac{2 \pi}{L_{y}} \mathbf{e}_{y}+\frac{2 \pi}{L_{z}} \mathbf{e}_{z} .
$$


Denote by $L_{x}$ the wavelength in the direction perpendicular to the surface of the plate. For free plates with a multiple of $L_{x} / 2$, the reflection coefficient is significantly reduced. For plates with thickness $L_{x} / 4+n L_{x} / 2$, ( $n$ is an integer), the reflection coefficient increases. (Note that the conditions of extremal reflection are reversed in the case of a monotonic change in the refractive indices in the layers [5]). At a frequency of 14.1 $\mathrm{GHz}$, the wavelength in a vacuum is $L_{0}=21.3 \mathrm{~cm}$. With normal incidence $(\alpha=0)$, the wavelength of isotropic ice is $11.9 \mathrm{~cm}$. In general

$$
L_{x}=\frac{L_{0}}{\sqrt{\mu \varepsilon-(\sin \alpha)^{2}}}=\frac{21.3}{\sqrt{3.18-(\sin \alpha)^{2}}} .
$$

As the angle $\alpha$ increases, the measuring device records the waves with increasing wavelength $L_{x}$. Therefore, the conditions of extreme reflection are different at different angles. Fig. 2 shows the theoretically calculated dependences for isotropic ice on the angle $\alpha$ for $L_{\chi}, L_{y}$, and the angle of refraction. For isotropic ice, the value of $L_{x}$ varies from $11.9 \mathrm{~cm}$ to $14.4 \mathrm{~cm}$ at different angles and leads to interference effects in the plates.
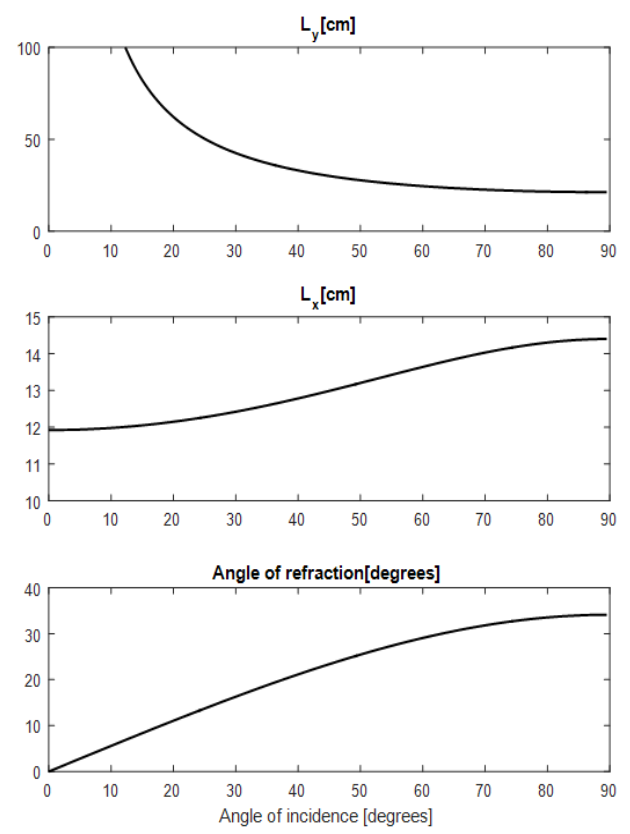

Fig. 2. The dependence of the wavelength $L$, the wavelength $L_{x}$ and the angle of refraction from the angle of incidence.

\section{THE EFFECT OF ANISOTROPY ON THE WAVELENGTH $L_{x}$}

Appendix shows modifications of Maxwell's equations in quasi-anisotropic media for plane linear harmonic (monochromatic) waves of $s$ and $p$-polarization. In the case of $x$-anisotropy, we denote $L_{x}$ by $L_{x x}$. Let $u_{x}=0.15$ be the $x$-anisotropy coefficient. Accordingly, we denote $L_{x, y}, u_{y}$ and $L_{x, z}, u_{z}$ for the cases of $y$ - and $z$-anisotropies. The relative dielectric constant and other coefficients are written as:

$\varepsilon_{11}=\varepsilon\left(1+u_{\chi}\right), \varepsilon_{22}=\varepsilon_{33}=\varepsilon ; \varepsilon_{31}=\varepsilon_{32}=\varepsilon_{12}=0$; $\mu=1$;

$\frac{\omega}{c}=k_{0}=\frac{2 \pi}{L_{0}}, k_{x}=\frac{2 \pi}{L_{x, x}}, k_{y}=k_{0} \sin \alpha$.

$x$-anisotropy affects only $p$-polarized waves and does not affect $s$-polarized waves. The conditions for the existence of solutions for $p$-waves are converted to:

$\varepsilon^{2}\left(1+u_{x}\right)-\varepsilon\left(k_{y} / k_{0}\right)^{2}-\varepsilon\left(1+u_{x}\right)\left(k_{x} / k_{0}\right)^{2}=0$.

From here we get the wavelength $L_{x x}$. We represent it in terms of the length $L_{x}$ for an isotropic medium and the correction for anisotropy proportional to $u_{x}$ :

$$
L_{x, x}=\frac{L_{0}}{\sqrt{\varepsilon-\frac{(\sin \alpha)^{2}}{1+u_{x}}}} \approx L_{x}-\frac{L_{x}^{3}(\sin \alpha)^{2}}{2 L_{0}^{2}} u_{x} .
$$

As $L_{x}$ should take the values shown in Fig. 2, depending on the angle of incidence. In the case of $15 \%$ anisotropy, this correction monotonously grows from zero to $0.6 \mathrm{~cm}$ when the angle of incidence varies from zero to $90^{\circ}$.

If the anisotropy axis is directed along the $y$ axis, then the wavelength $L_{x, y}$ is equal to:

$$
L_{x, y}=\frac{L_{0}}{\sqrt{\left(\varepsilon-(\sin \alpha)^{2}\right)\left(1+u_{y}\right)}} \approx L_{x}-\frac{L_{x}}{2} u_{y} .
$$

If the anisotropy axis is directed along the $z$ axis, then the anisotropy does not affect the $p$-polarization. The condition for the existence of a solution for $s$-polarization takes the form $\varepsilon(1$ 
$\left.+u_{2}\right)-\left(k_{y} / k_{0}\right)^{2}-\left(k_{x} / k_{0}\right)^{2}=0$. The wavelength $L_{x, z}$ is written as:

$$
L_{x, z}=\frac{L_{0}}{\sqrt{\left.\varepsilon\left(1+u_{z}\right)-(\sin \alpha)^{2}\right)}} \approx L_{x}+\frac{\varepsilon L_{x}^{3}}{2 L_{0}^{2}} u_{z} .
$$

In all subsequent graphs, the anisotropic case is represented by solid curves, and the isotropic case is represented by curves consisting of points.

\section{ENHANCING THE INFLUENCE OF X-ANISOTROPY BY INTERFERENCE EFFECTS}

In accordance with the multiplier $(\sin \alpha)^{2}$ in formula (1), anisotropy in the $x$-direction can occur only at sufficiently large angles of incidence and for sufficiently thick plates. For angles greater than $80^{\circ}$, the wavelength in an isotropic medium can be estimated as $14.3 \mathrm{~cm}$. The correction for anisotropy of $15 \%$ is $0.6 \mathrm{~cm}$ (see section 3), the result is a value close to 15 $\mathrm{cm}$. Therefore, at plate thicknesses of a factor of $7.5 \mathrm{~cm}$, on the curves of the reflection and transmission coefficients, the effects of extreme reflection should be observed for the anisotropic case.
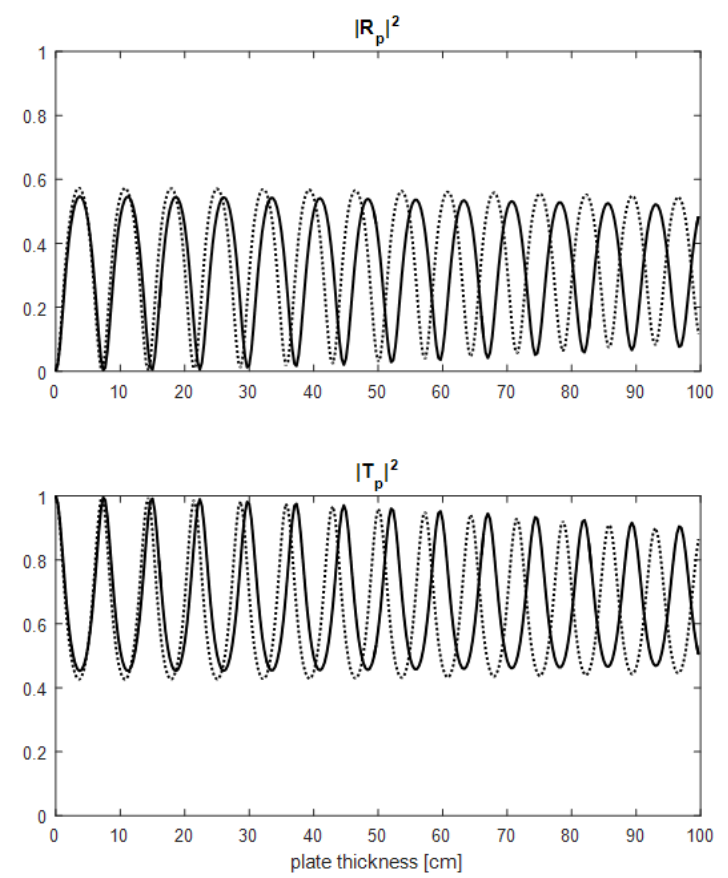

Fig. 3. The dependence of the reflection and transmission coefficients on the thickness of the free plate at an observation angle of $80^{\circ}$.
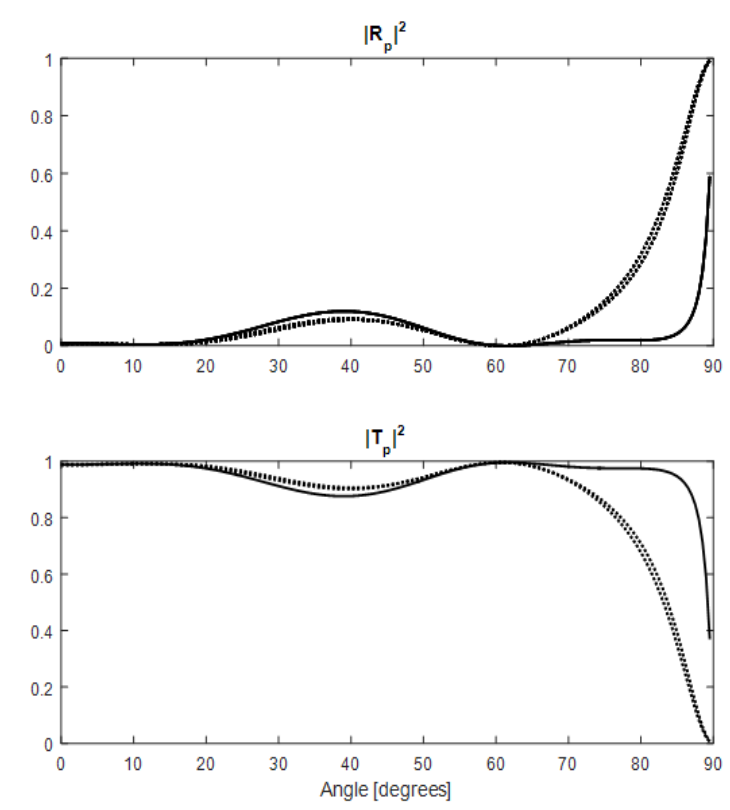

Fig. 4. The reflection and transmission coefficients of ice at a plate thickness of $30 \mathrm{~cm}$.

Fig. 3 shows the reflection and transmission coefficients at ice thicknesses from $0 \mathrm{~cm}$ to 100 $\mathrm{cm}$ for $p$-polarized waves incident at an angle of $80^{\circ}$. Due to the difference in the wavelength in the $x$-direction in an isotropic and anisotropic medium with an ice thickness of $85 \mathrm{~cm}$, the oscillations are in antiphase.

Fig. 4 shows the curves for $p$-polarization for a thickness of $30 \mathrm{~cm}$. Size $30 \mathrm{~cm}$ is a multiple of $6 \mathrm{~cm}$ and $7.5 \mathrm{~cm}$. At angles of $0^{\circ}-15^{\circ}$, the reflection is small. In addition, for anisotropic plates, low reflection occurs at large angles $\left(60^{\circ}-80^{\circ}\right)$.

Recall that the polarization-angledependences are depicted in the figures in the anisotropic case by solid curves, and in the isotropic case - by curves consisting of points.

\section{EXAMPLES OF AREAS OF TRANSPARENCY IN SINGLE-LAYER AND THREE-LAYER PLATES.}

Fig. 5 shows the dependence on the angle of incidence of the reflection coefficients and the transmission of a plate $50 \mathrm{~cm}$ thick. For isotropic ice, an area of transparency takes place at an angle of $30^{\circ}$. An elliptically polarized wave should pass without reflection and with low 

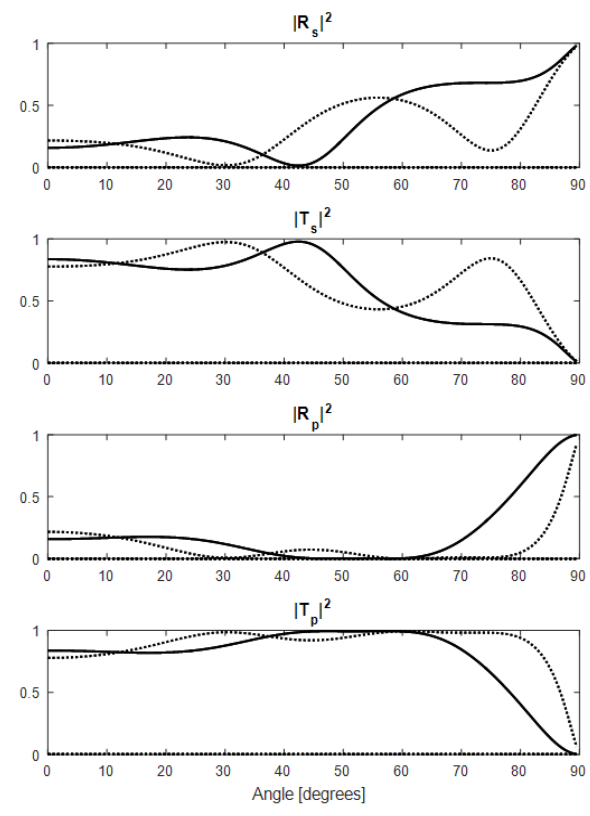

Fig. 5. The reflection and transmission coefficients of ice at a single-layer plate thickness of $50 \mathrm{~cm}$ z-anisotropy and $y$-anisotropy.

losses. The transparency region is destroyed due to the influence of $y$-anisotropy or z-anisotropy in $15 \%$. The curves of the anisotropic case are shifted relative to the curves of the isotropic case: for $s$-polarization under the influence of z-anisotropy, or for $p$-polarization under the influence of $y$-anisotropy.
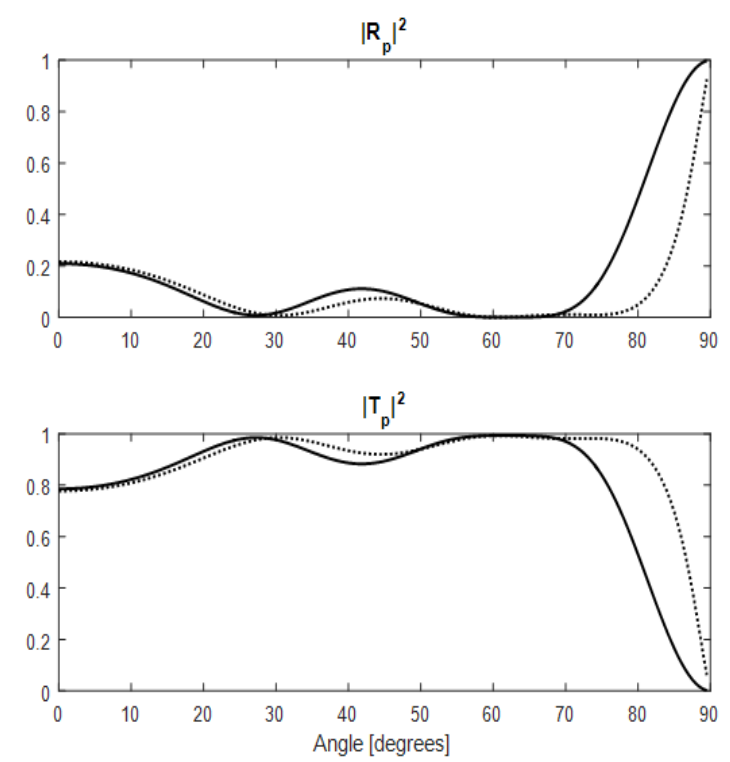

Fig. 6. The reflection and transmission coefficients of ice at a single-layer plate thickness of $50 \mathrm{~cm} x$-anisotropy.
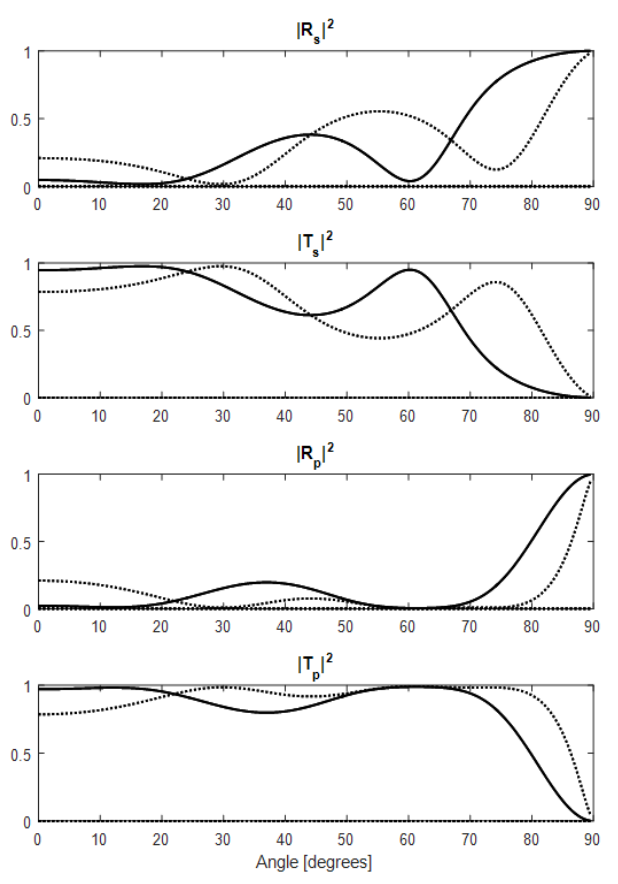

Fig. 7. The reflection and transmission coefficients of ice of a three-layer plate with different anisotropies.

Fig. 6 illustrates the effect of anisotropy in the $\mathrm{x}$ direction for a plate with the same thickness of $50 \mathrm{~cm}$ as in the previous figure. But the anisotropy axis is $15 \%$ orthogonal to the plate surface ( $x$-anisotropy). In the region of $30^{\circ}$ the blue line shifts within a few degrees. Transparency region is not destroyed.

Fig. 7 shows the reflection and transmission coefficients for the case when the plate with a total thickness of $50 \mathrm{~cm}$ (as in the previous case) is divided into 3 sublayers of the same thickness. In the first sublayer, there is a $15 \%$ $x$-anisotropy, in the second, $y$-anisotropy, in the third, z-anisotropy. Isotropic and anisotropic ice curves differ at all angles. The region of low reflection of the $s$-polarization is shifted to the Brewster angle and the transparency region is formed there. As a result of the combined influence of all types of anisotropy, another area of increased transparency is formed at angles of incidence of $0^{\circ}-20^{\circ}$. 
7. MAXIMUM THICKNESS OF ICE PLATES OF OBSERVATION OF INTERFERENCE STRUCTURES IN THE L-BAND

In Fig. 8, the reflection and transmission coefficient curves for plates with a thickness of $98,99,100,101,102 \mathrm{~cm}$ are shown in the same figure. These thicknesses differ from the average by no more than $2 \%$, but the oscillations of the curves differ significantly and merge into a wide strip. For plates of ice about a meter thick, these oscillations should complicate radiometric measurements.

Fig. 3 shows the variations of the reflection and transmission coefficients at an angle of incidence of $80^{\circ}$. There is a slow decrease in the amplitude of oscillations. It is due not to the absorption of waves, but to interference effects arising from the finite width of the radiometer's passband [11]. The maximum thickness of the plate can be estimated by the formula

$$
d=\frac{\lambda f}{2 \Delta f}=423 \mathrm{~cm},
$$
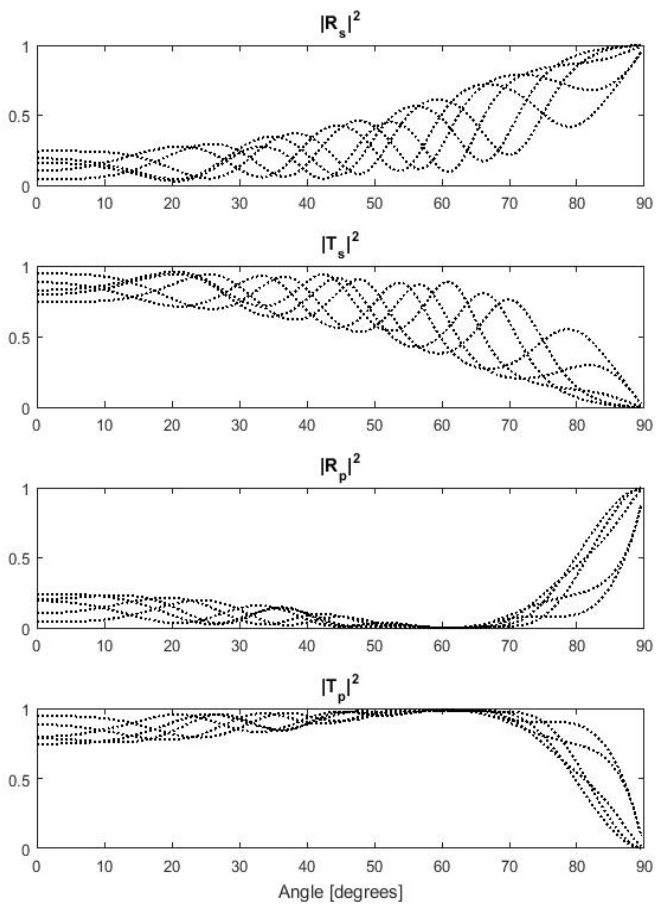

Fig. 8. The reflection and transmission coefficients of isotropic ice with a plate thickness of 98, 99, 100, 101, $102 \mathrm{~cm}$. $\lambda$ - wavelength; $f=14.1 \mathrm{GHz}-$ frequency; $\Delta f=$ $0.02 \mathrm{GHz}$ - radiometer band.

Fig. 9 shows the reflection and transmission coefficients for $p$-polarized waves with a slightly smaller thickness, $400 \mathrm{~cm}$. Oscillations on curves for anisotropic ice due to interference effects are noticeable. With a larger plate thickness, the amplitudes of interference oscillations decrease, become imperceptible, but exist.

\section{CONCLUSION}

The polarization-angular dependences of the reflection and transmission coefficients of smooth ice plates for radiometric measurements at a frequency of $1.41 \mathrm{GHz}$ with a bandwidth of $20 \mathrm{MHz}$ are theoretically considered.

When the anisotropy coefficient of ice is $15 \%$, the effect of anisotropy on the reflection and transmission coefficients of infinitely thick plates is insignificant, of the order of a few percent for anisotropy $y$ - and $z$-, and for $x$-anisotropy this effect is even less. These estimates are changed when taking into account the thickness of the plates.
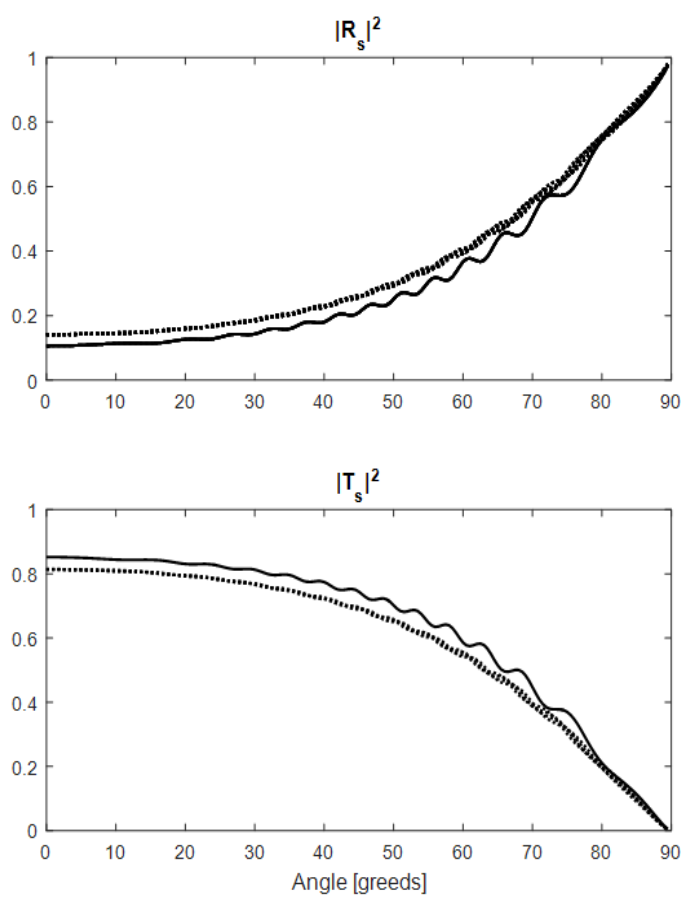

Fig. 9. Reflection and transmission coefficients of s-polarized ice at a thickness of $400 \mathrm{~cm}$. 
The wavelength in the direction orthogonal to the surface of the plate inside isotropic ice, at a frequency of $1.41 \mathrm{GHz}$, is $L_{x}=11.9 \mathrm{~cm}$. This means that the behavior of the reflection and transmission coefficients changes as the thickness of the ice plate changes every $L_{x} / 4 \approx 3$ $\mathrm{cm}$. When the plate thickness changes, there are oscillations of the reflection and transmission coefficients. Between oscillations of the coefficients corresponding to the isotropic and anisotropic case, a phase difference appears that increases with increasing plate thickness, and the effect of relative errors in thickness values on the reflection and transmission coefficients increases. The decrease in the amplitude of oscillations with increasing plate thickness is due to the presence of a limited radiometer frequency band in the frequencies [11].

$$
d=\frac{\lambda f}{2 \Delta f}=423 \mathrm{~cm}
$$

- maximum thickness of the ice plate, at which interference effects are already invisible.

The knowledge of more accurate values of $L_{x}$ makes it possible to interpret the phenomena of extremal reflection arising in plane-parallel ice plates less than $423 \mathrm{~cm}$ thick, depending on polarization, viewing angle and ice anisotropy. Assuming that anisotropy is small and ice can be considered a uniaxial crystal, in which the anisotropy axis coincides with one of the coordinate axes, formulas for $L_{x}$ are derived. The versions of formulas in the form of corrections due to anisotropy are given (formulas (1) - (3) in section 3).

The model of quasi-anisotropic media [15] (see also Appendix) makes it possible to take into account the anisotropy of the medium, without going beyond the concepts associated with the Fresnel formulas. Interference phenomena enhance the effect of anisotropy. The influence of $x$-anisotropy becomes significant at angles of more than $70^{\circ}$ and ice thicknesses of several tens of centimeters. If the anisotropy axis is parallel to the plane of the plate, then the interference effects of anisotropy change the reflection and transmission coefficients of the plates in the whole range of angles. The possibility of forming regions of transparency in free plates of ice is theoretically shown. It was verified that the Brewster angle does not depend on the anisotropy of ice. It is shown that transparency regions can be associated with the Brewster angle, but they can also arise at other angles. Anisotropy both destroys areas of transparency, and can contribute to the formation of such areas.

The shorter the wavelength, the smaller the required antenna size. The advantage of the $L$-range theoretical study is that in this range, it is possible to use simpler mathematical models with dielectric constant values known from the literature, the Debye formula remains valid. While in the range of $3 \mathrm{GHz}-100 \mathrm{GHz}$, the theoretical explanation of the passage of microwave radiation should be more complex. The obtained numerical estimates of the linear problem can be recalculated for radiometers with shorter wavelengths and used as an approximation for a more detailed study of the properties of ice in other ranges. However, with such a transfer of results, one should take into account the ratio of the radiometer band size to its frequency, the possibility of a more complex behavior of the dielectric constant and its dispersion.

In this paper, only free plates are considered. This fact limits the application of the numerical results obtained mainly by laboratory experiments. For solving the problems of monitoring the earth's surface (and a number of other problems), it would be useful to generalize the algorithms for obtaining transmittance for the case of arbitrary quasi-anisotropic environments. The behavior of the reflection and transmission coefficients for such cases should repeat the same oscillations as in the case of a free plate, with the same wavelengths, but with a different attenuation and phase shift. 
The work was carried out within the framework of the state task.

\section{APPENDIX}

Permissible components of the dielectric and magnetic permeability tensors for quasianisotropic media

Restrictions on the dielectric and magnetic permeability tensors for which TE- and/or TMwaves exist (with the field structure $\left(H_{x}, H_{,}, E_{2}\right)$ or $\left.\left(-E_{x},-E_{y}, H_{2}\right)\right)$ were considered in [13-15] and the corresponding generalized Fresnel formulas were obtained. In [15], the conditions for the existence of TE- and TM-waves were proposed to be considered as a definition of a special class of media: quasi-anisotropic media. Quasianisotropic media include all isotropic media and some anisotropic media. For multilayer plates of quasi-anisotropic media, algorithms have been constructed that generalize the Fresnel-Airy formulas [15]. The results of this paper were obtained using generalized algorithms and were verified using estimates using the usual Fresnel and Fresnel-Airy formulas. (We also used integration over the radiometer bandwidth and comparing the results with [11]). The concept of quasi-anisotropic media and the ability to solve Fresnel problems for multilayer plates with smooth boundaries from such media expands the range of solvable problems of electromagnetic wave propagation.

Let us write down the permittivity and magnetic permeability tensors admissible for quasi-anisotropic media. The icon $x$ indicates the permissible components on which the properties of the corresponding waves do not depend.

For $s$-waves with

$$
\widehat{\boldsymbol{\varepsilon}}=\left(\begin{array}{ccc}
\times & \times & 0 \\
\times & \times & 0 \\
\times & \times & \varepsilon_{33}
\end{array}\right) ; \hat{\boldsymbol{\mu}}=\left(\begin{array}{ccc}
\mu_{11} & \mu_{12} & \times \\
\mu_{21} & \mu_{22} & \times \\
0 & 0 & \times
\end{array}\right)
$$

Maxwell's equations for the amplitudes of monochromatic waves take the form: $\left(\begin{array}{ccc}\mu_{11} & \mu_{12} & -\frac{c}{\omega} \mathrm{k}_{y} \\ \mu_{21} & \mu_{22} & \frac{c}{\omega} \mathrm{k}_{x} \\ -\frac{c}{\omega} \mathrm{k}_{y} & \frac{c}{\omega} \mathrm{k}_{x} & \varepsilon_{33}\end{array}\right)\left(\begin{array}{l}H_{x} \\ H_{y} \\ E_{z}\end{array}\right)=0$.

Media of this type may be called $s$-quasi-anisotropic.

For $p$-waves at

$\widehat{\boldsymbol{\varepsilon}}=\left(\begin{array}{ccc}\varepsilon_{11} & \varepsilon_{12} & \times \\ \varepsilon_{21} & \varepsilon_{22} & \times \\ 0 & 0 & \times\end{array}\right) ; \quad \hat{\boldsymbol{\mu}}=\left(\begin{array}{ccc}\times & \times & 0 \\ \times & \times & 0 \\ \times & \times & \mu_{33}\end{array}\right)$

Maxwell's equations for the amplitudes of monochromatic waves take the form:

$\left(\begin{array}{ccc}\varepsilon_{11} & \varepsilon_{12} & -\frac{c}{\omega} \mathrm{k}_{y} \\ \varepsilon_{21} & \varepsilon_{22} & \frac{c}{\omega} \mathrm{k}_{x} \\ -\frac{c}{\omega} \mathrm{k}_{y} & \frac{c}{\omega} \mathrm{k}_{x} & \mu_{33}\end{array}\right)\left(\begin{array}{c}-E_{x} \\ -E_{y} \\ H_{z}\end{array}\right)=0$.

Media of this type may be called p-quasi-anisotropic.

Maxwell's equations for $s$ - and $p$-waves are satisfied simultaneously when

$\widehat{\boldsymbol{\varepsilon}}=\left(\begin{array}{ccc}\varepsilon_{11} & \varepsilon_{12} & 0 \\ \varepsilon_{21} & \varepsilon_{22} & 0 \\ 0 & 0 & \varepsilon_{33}\end{array}\right) ; \hat{\boldsymbol{\mu}}=\left(\begin{array}{ccc}\mu_{11} & \mu_{12} & 0 \\ \mu_{21} & \mu_{22} & 0 \\ 0 & 0 & \mu_{33}\end{array}\right)$.

Environments of this type can be called quasi-anisotropic environments in the narrow sense. In media of this type, the $s$ - and $p$-polarization waves do not interact. Algorithms that generalize the Fresnel and Fresnel-Airy formulas [15] are constructed. In anisotropic media, the wave vectors (wavelengths and angles of refraction) for $s$ - and $p$-polarizations may differ. In uniaxial crystals, when the direction of the anisotropy axis is parallel or orthogonal to the plate surface, the $s$-wave and $p$-polarization waves can be interpreted in terms of the optics of anisotropic media as "ordinary" and "extraordinary" waves. If the anisotropy axis 
is directed along the $z$ axis, then a wave with $p$-polarization is an "ordinary" wave and does not depend on anisotropy; a wave with $s$-polarization is an "extraordinary" wave and depends on the anisotropy coefficient. If the anisotropy axis lies in the $(x, y)$ plane, the situation is the opposite. A wave with $p$-polarization is an "extraordinary" wave and depends on anisotropy; a wave with $s$-polarization is an "ordinary" wave and does not depend on the anisotropy coefficient.

\section{REFERENCES}

1. Landau LD, Lifshitz EM. Course of Theoretical Physics. Volume 8. Electrodynamics of Continuous Media. Moscow, Fizmatlit Publ., 2003, 656 p.

2. Fedorov FI. Optika anizotropnykh sred [Optics of anisotropic media]. Minsk, AN BSSR Publ., 1958, 380 p.

3. Agronovich VM, Ginzburg VL. Kristallooptika $s$ uchetom prostranstvennoy dispersii $i$ teoriya eksitonov [Crystal optics with spatial dispersion and the theory of excitons]. Moscow, Nauka Publ., 1965, 374 p.

4. Born M, Wolf E. Principles of optics. Electromagnetic Theory of Propagation, Interference and Diffraction of Light. Pergamon Press, 1964.

5. Rozenberg GV. Optika tonkosloynykh pokrytiy [Optics of thin-layer coatings]. Moscow, State Publishing House of Fizmatlit, 1958, 570 p.

6. Brekhovskikh LM. Volny v sloistykh sredakh. [Waves in stratified medium]. Moscow, Nauka Publ., 1973, 343p.

7. Gorshkov MM. Ellipsometriya. [Ellipsometry]. Moscow, Sovetskoe radio Publ., 1974, 200p.

8. Pirozhkov AS, Ragozin EN. Aperiodic multilayer structures in soft X-ray optics. Phys. Usp., 2015, 58 1095-1105.

9. Bushuev VA, Roshchupkina OD. Vliyanie tolshchin perekhodnykh sloev na effektivnost vozbuzhdeniya tonkoplenochnogo volnovoda [Influence of the thicknesses of transition layers on the excitation efficiency of a thin-film x-ray waveguide]. Bull. Russ. Acad.
Sci., Ser. Phys., 2007, 71:59 (in Russ.), https:/ / doi.org/10.3103/S1062873807010157.

10. Shutko AM. SVCH-radiometriya vodnoy poverkhnosti $i$ pochvogruntov [Microwave radiometry of water and ground surfaces]. Moscow, Nauka Publ., 1986, 188 p.

11. Evtikhov MG. Primenenie modeli FrenelyaEyri pri issledovanii rezonansnykh oscillyatsiy ploskikh elektromagnitnykh voln [The application of Fresnel-Airy model for research of resonance oscillations of plane electromagnetic waves]. Zhurnal Radioelektroniki (elektronny zhburnal), 2017, No. 9. Available at http://jre.cplire.ru/jre/ sep17/11/text.pdf (in Russ.).

12. Bespyatykh YI, Bugaev AS, Dikshtein IE. Poverkhnostnye polyaritony $\mathrm{V}$ kompozitnykh sredakh s vremennoy dispersiey dielektricheskoy i magnitnoy pronitsaemostey [Surface polaritons in composite media with temporal dispersion of dielectric and magnetic permeabilities]. FTT, 2001, 43(11):2043-2047 (in Russ.).

13. Evtikhov MG, Nikitov SA, Novichihin EP. Teoreticheskoe issledovanie spektrov TE-voln v mnogosloynykh plenkakh iz ferromagnitnykh i dielektricheskikh materialov [Theoretical study of spectra of TE-waves in multilayer films of ferromagnetic and dielectric materials]. Saratov, Saratov University Publishing House, 2013, 68 p.

14. Evtikhov MG. The Snellius and Fresnel ratios for electromagnetic waves with constant linear polarization. Journal of Communications Technology and Electronics, 2010, 55(8):855.

15. Evtikhov MG. Fresnel-Airy formulas for quasi-anisotropic media. Radioelectronics. Nanosystems. Information Technologies (RENSIT), 2018, 10(1):91-100, doi: 10.17725/ rensit.2018.091.

16. Basharinov AE, Tuchkov LT, Polyakov VM, Ananov N.I. Izmerenie radioteplovih i plazmennih izluchenii [Measurement of radiothermal and 
plasma radiation]. Moscow, Sovetskoe radio Publ., 1968, 390 p.

17. Armand NA, Tishchenko YuG, Savorskiy VP, Smirnov MT. O nauchnoy programme kosmicheskikh eksperimentov $\mathrm{V}$ khode ekspluatatsii KA "MKA-PN1" [About scientific program of space experiments in the course of exploitation of the space apparatus MKA-PN1]. Sovremennye problemy distantsionnogo zondirovaniya zemli iz kosmosa, 2009, 6(1):15-21 (in Russ.).

18. Tikhonov VV, Rayev MD, Sharkov EA, Boyarskiy DA, Repina I A, Komarova NYu. Cputnikovaya mikrovolnovaya radiometriya morskogo l'da polyarnykh regionov. Obzor. [Satellite microwave radiometry of sea ice of polar regions. Review]. Issledovaniye zemli iz. kosmosa, 2016, 4:65-84 (in Russ.).

19. Golunov VA, Barabanenkov YuN. Radiometricheskie metody izmereniya obshchey otrazhatelnoy sposobnosti, obshchey pronitsaemosti i kogerentnoy pronitsaemosti slabo pogloshchayushchego sloya sluchaynoy diskretnoy sredy v millimetrovom diapazone dlin voln [Radiometric methods of measurement of the total reflectivity, the total transmissivity and the coherent transmissivity of a weakly absorbing random discrete medium layer in the millimeter wavelengths range]. Proc. Progress In Electromagnetics Research Symp. (PIERS-2012). Moscow, Russia, August 1923, 2012, pp. 1415-1418 (in Russ.).

20. Golunov VA, Korotkov VA. Radiometricheskoye issledovaniye dielektricheskikh svoystv presnovodnogo l'da $\mathrm{v}$ diapazone millimetrovykh voln Radiometric study of the dielectric properties of freshwater ice in the range of millimeter waves.]. Preprint № 24(499) IRE $\mathrm{R} A N, 1988,24$ p. (in Russ.).

21. Golunov VA, Kuz'min AV, Skulachev DP, Khokhlov GI. Eksperimental'nyye spektry oslableniya, rasseyaniya i pogloshcheniya millimetrovykh voln $\quad \mathrm{v}$ sukhom svezhevypavshem snege [Experimental spectra of attenuation, scattering and absorption of millimeter waves in dry freshly fallen snow.]. Zhurnal radioelektroniki [elektronnyy z̧burnal]. 2016, №9. (in Russ.). URL: http://jre.cplire.ru/jre/sep16/4/text. pdf.

22. Smirnov MT, Yermakov DM, Maklakov SM, Khaldin AA, Maksimov AYe. Eksperiment po distantsionnomu SVCH radiometricheskomu sondirovaniyu Zemli v L-diapazone s malogo kosmicheskogo apparata, pervye rezultaty Experiment in passive microwave remote sensing of the Earth in L-band from a small satellite, the first results]. Sovremennye problemy distantsionnogo zondirovaniya zemli iz kosmosa, 2013, 10(3):142-149 (in Russ.).

23. Kaleschke L, Tian-Kunze X, Maaß N, Mäkynen M, Drusch M. Sea ice thickness retrieval from SMOS brightness temperatures during the Arctic freeze-up period. Geophysical Research Letters, 2012, 39:L05501, doi: 10.1029/2012GL050916.

24. Bordonskiy GS, Gurulev AA, Krylov SD, Tsyrenzhapov SV. Izucheniye voln Ginzburga-Pekara v ledyanykh pokrovakh $\mathrm{v}$ mikrovolnovom diapazone [Study of Ginzburg-Pekar waves in ice sheets in the microwave range]. Sovremennyye problemy distantsionnogo zondirovaniya zemli iz kosmosa, 2007, 4(1):267-272 (in Russ.).

25. Bordonskiy GS, Gurulev AA, Krylov SD, Tsyrenzhapov SV, Orlov AO. O koeffitsiyente otrazheniya elektromagnitnykh voln ot granitsy vozdukh-led $\mathrm{v}$ santimetrovom diapazone $[\mathrm{On}$ the reflection coefficient of electromagnetic waves from the airice boundary in the centimeter range]. Souremennyye problemy distantsionnogo zondirovaniya zemli iz kosmosa, 2008, 5(2):30-32 (in Russ.).

26. Lebedev GA, Sukhorukov KK. Rasprostraneniye elektromagnitnykh i 
akkusticheskikh voln $\mathrm{v}$ morskom l'du [Electromagnetic and acoustic waves propagation in sea ice]. Saint-Petersburg, Gidrometeoizdat Publ., 2001, 81 p.

27. Zatsepina GN. Svoystva $i$ struktura vody [Properties and structure of water]. Moscow, Lomonosov MGU Publ., 1974, 168 p.

28. Bogorodskiy VV, Khokhlov GP. Anizotropiya dielektricheskoy pronitsayemosti i udel'nogo pogloshcheniya arkticheskogo dreyfuyushchego l'da $\mathrm{v}$ diapazone SVCH [Anisotropy of dielectric constant and specific absorption of arctic drift ice in the microwave range]. Zhurnal tekhnicheskoy fiziki, 1977, 47(6):1301-1305 (in Russ.).

29. Liebe HJ, Hufford GA, Manabe T. A model for the complex permittivity of water at frequencies below $1 \mathrm{THz}$. International Journal of Infrared and Millimeter Waves, 1991, 12(7):659-675.

30. Jonathan H. Jiang, Dong L. Wu. Ice and water permittivities for millimeter and submillimeter remote sensing applications. Atmos. Sci. Let., 2004, 5:146-151. 